\title{
Springer Link
}

\section{Learning from scientific texts: personalizing the text increases transfer performance and task involvement}

\author{
European Journal of Psychology of Education \\ October 2016, Volume 31, Issue 4, pp 499-513 | Cite as
}

- Stephan Dutke (1) Email author (stephan.dutke@psy.uni-muenster.de)

- Anna Christina Grefe (1)

- Claudia Leopold (1)

1. Institute for Psychology in Education, University of Muenster, , Münster, Germany

Article

First Online: 30 December 2015

- 427 Downloads

-3_Citations

\begin{abstract}
In an experiment with 65 high-school students, we tested the hypothesis that personalizing learning materials would increase students' learning performance and motivation to study the learning materials. Students studied either a 915-word standard text on the anatomy and functionality of the human eye or a personalized version of the same text in which 60 definite articles (e.g., "the eye") were replaced with 60 second-person possessive pronouns (e.g., "your eye"). Afterwards, participants answered comprehension and transfer questions. One week later, the participants were asked to restudy the text and to answer the same questions again with the aim to improve their performance. In the personalized text condition, students showed higher transfer performance, spent more time on restudying the text, and reported being more motivated than students in the standard text condition. However, only duration of restudying (not self-reported motivation) mediated the effect of personalization on transfer performance.
\end{abstract}

\section{Keywords}

Learning from texts Text comprehension Personalization of instruction materials Linguistic personalization Task involvement in learning from text

Claudia Leopold is now at the University of Fribourg, Switzerland. 


\section{Introduction}

Personalizing learning materials by directly relating the content to or addressing the learner has been used as a strategy to enhance learning performance. Two strategies of personalization can be distinguished in the literature. Instructional texts may be personalized by embedding the learning content in a context that is of particular importance to the learner or that reflects the learner's interest or experience (e.g., Cordova and Lepper 19.96). In other studies, instructional texts were personalized using purely linguistic personalization strategies, for example, by addressing the learner grammatically in the second person (e.g., Ginns and Fraser 2010). Numerous studies demonstrated that personalizing expository text (Ginns and Fraser 2010), narrated animations (Moreno and Mayer 2000; Mayer et al. 2004), illustrated text (Kartal 2010; Stiller and Jedlicka 2010), computer-based learning games (Cordova and Lepper 19.96), learning tests (Davis-Dorsey et al. 19.91), or utterances of pedagogical agents in computer-based learning programs (Moreno and Mayer 2004; Moreno et al. 2001) increased learning performance compared to nonpersonalized materials or instructions (for a meta-analysis, see Ginns et al. 2013).

How can the personalization effect be explained? Researchers have proposed that personalized materials increase the reader's motivation for processing the learning materials, which in turn may increase task involvement and thereby learning success (e.g., Anand and Ross 19 $\underline{87}$; Cordova and Lepper 19.9ㅁ; Davis-Dorsey et al. 199.91; Herndon 19877; Mayer 2005; Moreno et al. 2001; Ross and Anand 19867; Ross et al. 1986). This hypothesis received support from studies in which learning materials were personalized with regard to the learners' interest, experiences, or competences (e.g., Cordova and Lepper 199.96; Davis-Dorsey et al. 19.91). However, evidence from studies using only linguistic personalization strategies is less informative (e.g., Ginns and Fraser 2010; Mayer et al. 2004; Moreno and Mayer 2000). These studies particularly investigated whether motivational variables and learning performance varied as a function of personalization, but motivational variables have not been explicitly tested as to whether or not they mediate the personalization effect on learning performance. The present study was designed to advance this literature by investigating the mediation hypothesis using a linguistically personalized science text.

\section{Review of previous research}

In their influential study on personalizing learning materials, Cordova and Lepper (199.96) asked learners to answer a questionnaire referring to the learner's "favorite food, school subjects, hobbies, television shows, books and magazines” (p. 718). This information was used to individualize a computer-based learning game on arithmetic. For example, problems requiring addition, subtraction, multiplication, and division were embedded in fantasy contexts obtained from the answers that each learner provided on the personalization questionnaire-individually for each child. Other participants learned with a generic, nonpersonalized version of the game including the same tasks. Personalization increased not only math performance but also the students' motivation to use the game. Students learning with the personalized game liked the game more than students learning with the generic version. Personalization 
also affected behavioral indicators of task involvement assessed from the online recordings. Students in the personalized condition were more willing to stay after class to continue using the game, preferred more challenging versions of the game, used more complex arithmetic operations, and generated more strategic moves to outperform their opponents.

The Cordova and Lepper (19.96) results are consistent with previous studies claiming that personalized learning problems are more motivating (e.g., Anand and Ross 19 Herndon 197; Ross and Anand 197; Ross et al. 1986) and thus can be assumed to enhance involvement in the learning process compared to nonpersonalized problems (Davis-Dorsey et al. 19.911). Cordova and Lepper (19.96) assumed that entities (i.e., themes, objects, characters, activities) related to a learner are of higher interest than entities related to others. Increased interest has been shown to increase learning

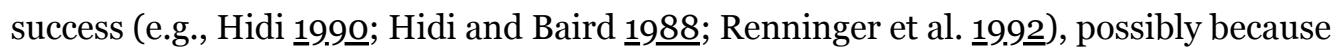
interest increases the amount of cognitive resources students are willing to invest in solving a learning problem.

Moreno et al. (2001) and Mayer (2005) also proposed that personalization enhances motivation although their argumentation was slightly different. They suggested that the motivation to invest cognitive resources in learning and comprehension would be a function of the social interpretation of the learning situation. The more learners perceive themselves as agents in a social interaction (e.g., with a learning partner or a teacher), the more they will be motivated to "make sense of what the speaker is saying" (Mayer 2005, p. 202), that is, to understand the contents of the communication (cf. Ginns et al. 2013, pp. 446-449). This increase in motivation does not necessarily require a "real" face-to-face interaction. Mayer's (2005) central assumption is that this kind of motivation can also be triggered by social cues used in indirect, media-based, or symbolic social interactions. For example, when interacting with a computer-based learning program or a software-based pedagogical agent or in reading a textbook, the reader becomes aware that the author had written the text with the intention to transmit information to the reader (see also Reeves and Nass 19.96). Thus, the personalization of learning materials or instruction can be conceived of as generating social cues (e.g., addressing the reader as an individual) similar to the cues found in real social interactions. Therefore, these cues are expected to increase the motivation to better understand the instruction or learning materials being communicated (Mayer 2005).

Personalizing learning materials in educational practice or research is extremely laborious and requires, as demonstrated by the Cordova and Lepper (19.9므) example, assessing the learners' characteristics, interests, competencies, or individual preferences. Therefore, researchers have sought more parsimonious and focused ways of personalizing instruction. A feasible strategy is to manipulate only the linguistic features of written or spoken text. A most important linguistic feature is whether or not the learner is addressed individually, for example, by using second-person constructions (e.g., "If your result is correct, ...") as opposed to a more formal, nonpersonalized style ("If the result is correct, ..."). Numerous studies employing this strategy (for a review, see Ginns et al. 2013) have demonstrated that even a purely linguistic personalization can increase learning success (e.g., Ginns and Fraser 2010; Kartal 2010; Mayer et al. 2004; Moreno and Mayer 2000, 2004; Moreno et al. 2001; Stiller and Jedlicka 2010). This effect was found in samples of 1oth grade, college, and 
university students ranging in mean age from 16 to 23 years. Learning materials referred to physical (stellar death) and biological topics (plants, human respiratory system, anatomy and function of the human heart and eye). The results do not indicate effects of age or learning subject on the personalization effect.

The evidence, however, from studies investigating linguistic personalization has failed to explain particular aspects of the personalization effect. For example, the extent that the effect is moderated or mediated by motivation or interest remains unclear. Three groups of results can be distinguished in which learner motivation or interest has been assessed as correlates. The first group of studies has found positive effects of linguistic personalization on the evaluation of the learning materials potentially relevant to motivation. Moreno et al. (2001), for example, introduced a pedagogical agent in a computer-based multimedia lesson that communicated with the learner in a conversational style and addressed the learner in the second person. The same information was presented by text and graphics in a nonpersonalized style in a control condition (Moreno et al. 2001, experiments 1 and 2). Students presented with the pedagogical agent reported more interest in the learning subject and in interacting with the learning system than students who learned with the nonpersonalized textpicture-based system. In a different study, Moreno and Mayer (2004) used an agentbased multimedia educational game. The agent spoke to the learner in a personalized informal style (using "I" and "you") or presented a nonpersonalized (third person) monologue. Consistent with Moreno et al. (2001) findings, the participants rated the personalized version of the system as more friendly, more helpful, and less difficult. However, no measures were used that directly addressed motivation or interest.

A second group of studies found personalization effects on motivation but only in interaction with other variables. Kartal (2010) investigated linguistically personalized versus nonpersonalized text and crossed this factor with formal versus informal linguistic elements available in Turkish (also in German or French) but not in English. For example, in English, unacquainted as well as intimately known communication partners are addressed with the personal pronoun "you," whereas in other languages such as Turkish, French, or German, different pronouns are used depending on whether the speaker wishes to address the listener in a formal or informal way. Kartal (2010) found that learning performance was higher reading the personalized/informal text than reading the nonpersonalized/formal text. The participants, however, described themselves as more motivated in the personalized/informal condition than in the personalized/formal and nonpersonalized/formal conditions. Thus, learning performance and self-reported motivation seemed to be affected by different interactions between text personalization and text formality. Stiller and Jedlicka (2010) found that learners with lower prior knowledge were more supported by the personalized text than learners with higher prior knowledge. Consistent with this pattern, low-prior-knowledge participants reported a higher task involvement than participants with higher prior knowledge when the materials were linguistically personalized. A different pattern of results was found by Brom et al. (2014). They presented participants with a computer-based simulation of a brewery with linguistically personalized vs. non-personalized explanations. Although participants showed higher task involvement learning with the personalized version, no differences in learning outcomes were found.

A third group of studies failed to find any effects of linguistically personalized 
materials on motivational variables. Moreno and Mayer (2000) presented students with a multimedia-based learning program and contrasted personalized versus nonpersonalized on-screen text messages (experiment 3) and personalized versus nonpersonalized text spoken by a pedagogical agent (experiments 4 and 5). Although personalization had an effect on learning performance, it had no effects on the participants' ratings of motivation and interest and the system's difficulty, friendliness, and helpfulness as perceived by the participants. Moreno and Mayer (2000) concluded that the positive effects of personalization on learning were not mediated by interest or motivation (p. 731). Mayer et al. (2004) presented students with a personalized (conversational) versus nonpersonalized (formal) narrated animation that explained the human respiratory system. Personalization increased learning success but did not influence ratings of interest. The same pattern was found by Ginns and Fraser (2010) using linguistically personalized versus nonpersonalized paper-based texts about anatomy. Personalization had no influence on the participants' ratings of interest, enjoyment, or experienced effort, although students learning with the personalized materials performed better on a retention test than students in the nonpersonalized condition. Consistent with these findings, the metaanalysis by Ginns et al. (2013) revealed no reliable effects of linguistic personalization on self-reported interest in the learning subject.

In sum, linguistically personalized learning materials were shown to enhance learning and comprehension in diverse contexts, but the effects on potentially mediating motivational variables were inconsistent. This inconsistency might be due to several factors. For example, many studies investigated this question in laboratory situations rather than in authentic learning situations in which learning success has a greater motivational impact. Moreover, the cited studies used multi-faceted motivational concepts. Studies focused on thematic interest as a facet of intrinsic motivation (e.g., Moreno et al. 2001), perceived supportiveness of the learning materials (e.g., Moreno and Mayer 2004), indicators of motivated behavior such as enjoyment or effort (e.g., Ginns and Fraser 2010), or self-reported achievement motivation (e.g., Kartal 2010). The diversity of motivation-related constructs might have complicated finding consistent patterns. Only two studies used behavioral indicators of motivation (Brom et al. 2014; Mayer et al. 2004), whereas all other studies relied on self-report measures

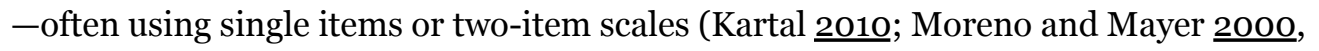
2004; Moreno et al. 2001). In only two studies, multiple-item measures were used and reliabilities were reported (Ginns and Fraser 2010; Stiller and Jedlicka 2010). Thus, the quality of the dependent measures might have hindered finding personalization effects on motivation-related variables. Most important, however, none of these studies explicitly tested the hypothesis that motivational variables mediated the personalization effect on learning performance.

\section{Goals and hypotheses}

The present study was designed to elucidate the role motivation plays in the linguistic personalization effect. Particularly, we aimed at testing the mediation hypothesis in an authentic school setting. We assessed comprehension and transfer as indicators of learning outcomes. Learning motivation was assessed by verbal reports and by registering the time learners engaged in the learning task. 
During their biology lesson, high-school students studied a linguistically personalized or nonpersonalized (standard) text on visual perception for a fixed duration and answered comprehension and transfer questions. One week later, the participants were again presented with the text and their previous answers to the comprehension and transfer questions. Then, unexpectedly, they had the opportunity to restudy the text and revise their answers for as long as they wished with the aim to improve their previous performance and understanding. The participants verbally reported on their motivation to improve previous learning performance. The individual duration of their restudy activities was registered as an indicator of learning task involvement.

We expected students studying the personalized text to perform better on comprehension and transfer items than students studying the standard text (Hypothesis 1). Given the assumption that personalized text should increase students' motivation of understanding the text thoroughly, we expected participants in the personalized text condition to restudy the text longer (Hypothesis 2) and to describe themselves as more motivated to complete the comprehension and transfer items than the students learning from the standard text (Hypothesis 3). Furthermore, we expected self-reported motivation (Hypothesis 4) and duration of restudying (Hypothesis 5) to mediate the personalization effect on learning performance.

\section{Method}

\section{Participants}

Sixty-five students (Grade 11) participated in this study. The 36 female and 29 male students attended biology courses at a German high school. Within their classes, participants were randomly assigned to the personalized text condition $(n=31 ; 19$ female; mean age $=16$.o years $)$ or to the standard text condition $(n=34 ; 17$ female; mean age $=15.9$ years). Data from six students who attended only the first or the second session were excluded. The final sample comprised $n=29$ students ( 18 female) in the personalized text condition and $n=30$ students ( 17 female) in the standard text condition.

\section{Materials}

Students studied a scientific text describing the structure and functioning of the human eye. The text was written by the authors and consisted of 915 words and one picture showing the components of the human eye in a horizontal section. The information presented in the text and the picture was taken from German biology textbooks written for students in the 11th and 12th grades. In the standard version of the text, the reader was not directly addressed, that is, first- and second-person constructions were avoided (see the Appendix for a sample passage). In the personalized version, 60 definite articles were replaced by second-person possessive pronouns (e.g., "your eye" instead of "the eye"). These changes required some more minor reformulations to assure continuity and coherence. For example, in the nonpersonalized version, the heading read "The human eye," whereas in the 
personalized version, it was "Your eye." Apart from these minor differences and the personalization manipulation, the two text versions were identical.

Students' prior knowledge was assessed with 10 items about human perception. Participants were required to provide a written explanation for terms presented in each item (e.g., "visual illusion"). Prior to the experiment, a list of criteria for valid explanations was created for each term. Based on these lists, two independent raters blindly evaluated the responses on a three-point scale $(\mathrm{o}=$ explanation is missing or unacceptable, 1 point = explanation is partially acceptable, 2 points $=$ complete and correct explanation). The inter-rater reliability across all 10 prior knowledge items was high $(r=0.98, p<0.001)$. Incongruent judgments were clarified by discussing the answer with a third rater. The maximum number of points that could be achieved was 20 , and the percentage of points obtained was used as a prior knowledge score.

The students' text comprehension was assessed by 13 one-sentence statements related to the text's contents. The participants' task was to evaluate the correctness of each statement. Seven of the statements were true and six were false (students had no knowledge of the proportion of true and false statements). The statements tapped students' conceptual understanding of the contents. For example, the statement "The pupil regulates the incidence of light" required that students remember the position of the pupil in the human eye and understand its mechanics. All information necessary to evaluate these statements appeared in the text, albeit differently formulated than in the test items. Thus, these statements could not be evaluated solely on the basis of remembering surface features of the text. Participants evaluated each statement on a four-point scale ("I am sure the statement is true"; "I think the statement is true, but I am not sure"; "I think the statement is false, but I am not sure"; "I am sure the statement is false"; see, e.g., Dutke et al. 2010). A correct and confident answer was scored 3 points; a correct and unconfident answer was scored 2 points. If the answer was incorrect but the participant indicated being unsure, 1 point was scored, and an incorrect answer given with confidence was scored o. Thus, the maximum number of points for the comprehension items was 39. The percentage of points obtained was used as an indicator of text comprehension.

Transfer of knowledge was tested by six tasks requiring the application of knowledge acquired from the text to solve new problems not mentioned in the text. For example, participants were presented with a drawing that showed the light path in an inadequately accommodated eye. The students were asked to describe the kind of accommodation problem that was displayed and explain in depth why this problem might have emerged and how it could be alleviated or corrected. Prior to the experiment, a list of criteria for valid explanations was created for each item. Based on these lists, two independent raters blindly evaluated the responses. For each criterion met, 1 point was scored. The number of points that could be achieved varied from 5 to 8 points depending on the complexity of the task. The inter-rater reliability across all five transfer items was high $(r=0.94, p<0.001)$. Incongruent judgments were clarified by discussing the answers with a third rater. The maximum number of points that could be achieved across all transfer items was 41, and the percentage of points obtained was used as a score indicating transfer performance.

Motivation to complete the comprehension and transfer tasks was rated with three items ("I was motivated to answer the questions as correctly as possible"; "I was 
motivated to revise my answers in the second session"; "I am curious about my learning result"; Cronbach's alpha $=0.75$ ) on a four-point rating scale ("I completely agree"; "I agree"; "I disagree"; "I completely disagree"). The score for self-reported motivation ranged between 1 and 4 with high values indicating high motivation.

\section{Design}

A two-group design (personalized vs. nonpersonalized text) with repeated measures (first vs. second study phase) on text comprehension and transfer performance was employed. Dependent variables were the scores for text comprehension, transfer performance, self-reported motivation, and the time spent restudying the text and revising the answers on the comprehension and transfer items. The scores for prior knowledge served as a control variable.

\section{Procedure}

The study was conducted during the students' regular biology courses at school. The experimenters explained that (a) the goal of the study was to explore how students learn with written science texts, (b) the topic will be human visual perception, (c) the participants will be tested on their acquired knowledge, and (d) the participants will receive individual feedback about their learning performance. The participants were unaware of the second session and the opportunity to restudy the text and revise their answers on the comprehension and transfer test. Participants worked on the prior knowledge items for $12 \mathrm{~min}$. After a short break, they were randomly given the personalized or the standard text, which they studied for $15 \mathrm{~min}$. Then they worked on the comprehension and transfer items for $60 \mathrm{~min}$. The students received no feedback about their learning performance.

One week later, the students were visited again in their school and informed that they could read the text again, check their answers, and try to improve their learning scores. The materials were handed out to the students, and they were informed that they could take as much time as they wished to clarify comprehension problems and to revise their answers to improve their test performance compared to their performance in the first session. The science text and the participants' previous answers were available throughout the entire restudy phase. Participants' restudy time was measured as the time until the participant indicated that they were unable to make further amendments. Another week later, the participants received individual feedback about their learning performance and were debriefed.

\section{Results}

Before testing the hypotheses, we checked whether the experimental groups differed with regard to their prior knowledge. Students in the personalized text group $(M=$ 42.8, $\mathrm{SD}=14.7)$ and the standard text group $(M=45.0, \mathrm{SD}=13.6)$ achieved similar mean scores in the prior knowledge test, which did not differ significantly, $t(57)=0.61$, $p=0.547, d=-0.158$ (95\% CI: LL $=-0.679$ to $\mathrm{UL}=0.364)$. 
We analyzed the text comprehension scores in a split plot ANOVA with type of text (personalized vs. standard text) as a between-participants factor and repeated measures on comprehension performance (first vs. second study phase). Comprehension performance increased from the first to the second study phase, $F(1$, $56)=11.22, p=0.001, d=0.217$ (95\% CI: LL $=0.087$ to UL $=0.347$, see Table 1 for means and standard deviations), whereas personalization had no significant effect, $F(1,56)<1$. The interaction term was also not significant, $F(1,56)<1$. Thus, inconsistent with Hypothesis 1, comprehension performance did not vary as a function of text personalization. Comprehension in the first and the second study phase were highly correlated $(r=0.88, p<0.001)$. Whereas the assumptions concerning homogeneity of variances and sphericity were fulfilled, the errors tended to be nonnormally distributed. Therefore, we validated the result with non-parametric tests which confirmed the previous results. Comprehension performance increased from the first to the second test ( $p=0.002$ ) but did not vary with personalization (first study phase: $p=0.913$; second study phase: $p=0.973$ ).

\section{Table 1}

Comprehension and transfer performance: means and standard deviations

\section{Type of text}

\section{Standard Personalized}

\section{Study Restudy Study Restudy}

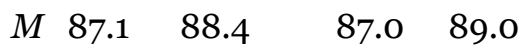

Comprehension

$\begin{array}{lllll}\text { SD } 7.6 & 8.1 & 7.3 & 7.5 \\ M & 38.0 & 42.4 & 53.7 & 57.8\end{array}$

Transfer

SD $13.1 \quad 14.4 \quad 13.4 \quad 14.7$

Comprehension and transfer scores are presented as the percentage of points obtained.

Second, we analyzed the transfer scores in a split-plot ANOVA 1 with type of text (personalized vs. standard text) as a between-participants factor and repeated measures on transfer performance (first vs. second study phase). The assumptions concerning homogeneity of variances, sphericity, and normality of errors were fulfilled. Two main effects emerged (see Table $\underline{1}$ for means and standard deviations). The transfer scores increased from the first to the second study phase, $F(1,57)=26.21$, $p<0.001, d=0.306$ (95\% CI: LL $=0.186$ to $\mathrm{UL}=0.426$ ). Moreover, consistent with Hypothesis 1, a personalization effect was found. The transfer scores were higher when students learned with the personalized text than when they learned with the standard 
text, $F(1,57)=19.37, p<0.001, d=1.116$ (95 \% CI: $\mathrm{LL}=0.608$ to $\mathrm{UL}=1.623$ ). The interaction term was not significant, $F(1,57)<1$. Transfer performance in the first and the second study phase were highly correlated $(r=0.92, p<0.001)$.

Students spent a longer time on restudying the personalized text than restudying the standard text $t(57)=2.02, p=0.024$ (one-tailed test), $d=0.540$ (95\% CI: LL $=0.004$ to $\mathrm{UL}=1.047$, see Table $\underline{2}$ for means and standard deviations). This result is consistent with Hypothesis 2 and indicates greater task involvement in the personalized condition.

\section{Table 2}

Time spent restudying and self-reported motivation: means and standard deviations

\section{Type of text}

\section{Standard Personalized}

$$
M 8.82 \quad 11.37
$$

Duration study phase

$\begin{array}{lll}\text { SD } 2.92 & 6.22 \\ M \quad 2.13 & 2.41\end{array}$

Self-reported motivation

$$
\text { SD } 0.56 \quad 0.65
$$

Duration of the restudy phase was measured in minutes. The score for self-reported motivation could vary between 1 and 4 with higher values indicating higher motivation.

With regard to self-reported motivation, the students in the personalized text group reported slightly higher values than the students in the standard text group, $t(57)=$ 1.74, $p=0.044$ (one-tailed test), $d=0.470$ (95\% CI: LL $=-0.069$ to UL $=0.974$, see Table $\underline{2}$ for means and standard deviations). This result tends to be consistent with Hypothesis 3 .

To test whether motivation mediated the effect of linguistic text personalization on transfer performance in the restudy phase, we conducted two mediator analyses. The first analysis included duration of restudying as a potential mediator; the second analysis included self-reported motivation as a potential mediator. We followed the

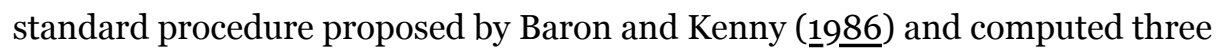
separate single-predictor regression analyses. They showed that personalization significantly predicted transfer performance and the duration of the restudy phase (see Fig. 1). Moreover, duration of the restudy phase alone significantly predicted transfer performance (Fig. 1). The fourth (stepwise) regression analysis with transfer performance as the dependent variable included duration of the restudy phase as the 
first predictor and then personalization was entered. The results show that the effect of personalization on transfer performance was reduced but still significant.

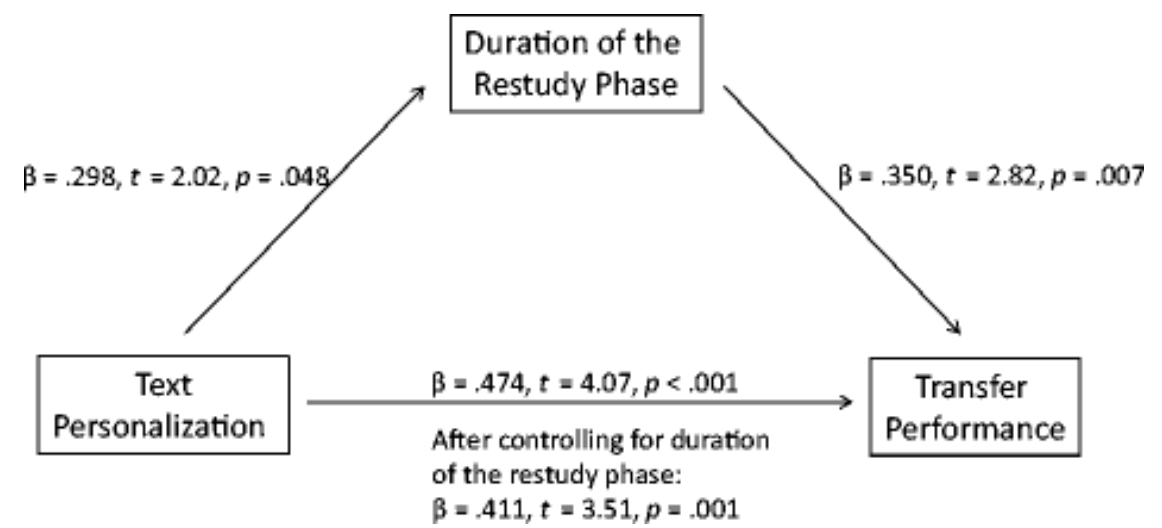

Fig. 1

Duration of restudying as a mediator of the personalization effect on transfer performance. Arrows designate the direction of prediction (from the predictor to the dependent variable)

One shortcoming of the Baron and Kenny approach is that it fails to directly address the mediation hypothesis-the indirect effect of personalization on transfer performance through the mediator duration of restudy phase (Hayes 2009; Preacher and Hayes 2004). This indirect effect is the product of the effect of personalization on duration of restudy phase (path $a$ ) and the effect of duration of restudy phase on transfer performance (path $b$ ) while controlling the effect of personalization resulting in the product coefficients $a b$. We tested the significance of the indirect effect by using the bootstrapping procedure. Bootstrapping is the preferred method for small samples because it is independent from distributional assumptions regarding the indirect effect $a b$, which tends to be asymmetric (Bollen and Stine 1990; Preacher and Hayes 2004). Bootstrapping works by repeatedly drawing samples from the original sample and computing the indirect effect $a b$, an estimated standard error, and confidence intervals for the indirect effect. If zero is not included in the confidence interval, the mediating effect is interpreted to be significant. According to recommendations of Hayes (2009), our analysis was based on 5000 bootstrap samples. Consistent with Hypothesis 4, our results show that the duration of the restudy phase mediated the effect of personalization on transfer performance: bootstrapped estimate of the indirect effect $a b=2.04, \mathrm{SE}=1.29(95 \% \mathrm{CI}: \mathrm{LL}=0.012$ to $\mathrm{UL}=5.02)$.

An analog analysis was computed with self-reported motivation as a potential mediator (see Fig. 2). First, we followed the Baron and Kenny procedure. The singlepredictor regression analyses demonstrated that personalization significantly predicted transfer performance but not self-reported motivation. Self-reported motivation, however, significantly predicted transfer performance. When personalization was entered as the second predictor after self-reported motivation, the $\beta$ weight of personalization was still significant but lower than the $\beta$ when personalization was included as the only predictor (see Fig. 2). To test the significance of the indirect effect, we used the bootstrapping approach (based on 5000 bootstrap samples). Contrary to Hypothesis 5, self-reported motivation did not mediate the effect of personalization on transfer performance: bootstrapped estimate of the indirect effect $a b=2.96, \mathrm{SE}=1.91$ (95\% CI: $\mathrm{LL}=-0.397$ to UL $=7.311$ ). Thus, while the duration of the restudy phase supported our mediation hypothesis, self-reported 
motivation was not found to significantly mediate the effect of personalization on transfer.

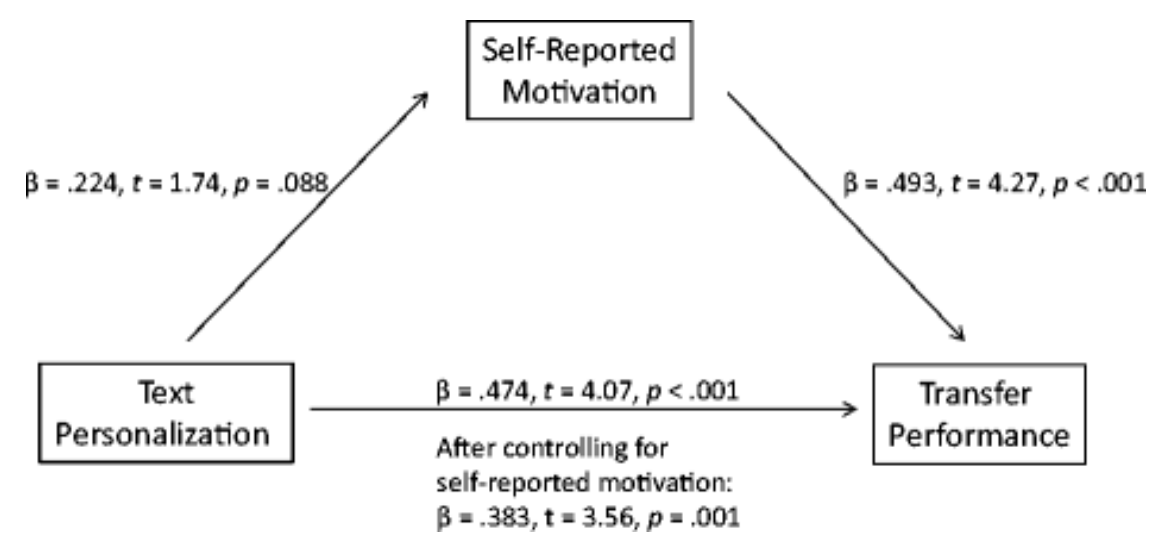

Fig. 2

Self-reported motivation as a mediator of the personalization effect on transfer performance. Arrows designate the direction of prediction (from the predictor to the dependent variable)

\section{Discussion}

We investigated whether the personalization effect can be demonstrated in an authentic school setting using conventional written text. Consistent with Hypothesis 1, linguistically personalizing the science text had a positive effect on transferring knowledge acquired from the text to new problems. This finding is particularly important for two reasons. First, the effect of linguistic personalization was found under authentic conditions during regular school lessons, which points to further applications of the personalization effect in educational settings. Second, the effect was demonstrated using a conventional paper-based text. This is remarkable given that most other studies used computerized learning programs or multimedia learning environments (Mayer et al. 2004; Moreno and Mayer 2000; Moreno et al. 2001; Stiller and Jedlicka 2010). Previous studies using written text provided less conclusive results. Ginns and Fraser (2010) measured retention performance as the main dependent variable, whereas our study demonstrated a personalization effect on transfer performance, which is consistent with most of the multimedia-based studies (Ginns et al. 2013; Mayer et al. 2004; Moreno and Mayer 2000; Moreno et al. 2001; Stiller and Jedlicka 2010). Other authors manipulated not only the linguistic form but also vocabulary and syntax (e.g., Bretzing and Kulhavy 1981) or employed text genres different from instructional text (e.g., Wagner et al. 199.9). Thus, the present result contributes to evidence that linguistic personalization can improve deep understanding of paper-based instructional text. This result is also theoretically relevant because personalization was found to be effective even with a more traditional medium that is less interactive compared to multimedia systems that usually provide diverse interactive and dynamic features such that personalized text features are more salient to the learner. This result is practically relevant because paper-based written text is still essential in many educational settings.

The result that the personalized text used in the present study did not foster performance on the comprehension items is probably due to a ceiling effect. The mean 
scores on the comprehension items varied between 87 and $89 \%$ correct with standard deviations between 7.3 and $8.1 \%$. These data suggest that the comprehension items were too easy to detect an effect of personalization. This assumption is consistent with the result that the personalization manipulation affected performance on the transfer items, which were more difficult with mean scores between 38 and $58 \%$ correct. Nevertheless, studies not limited by a ceiling effect also consistently found greater effects on transfer performance than on retention or comprehension performance (Mayer et al. 2004; Moreno and Mayer 2000; Moreno et al. 2001; Stiller and Jedlicka 2010). This pattern is also reflected in the meta-analysis by Ginns et al. (2013) showing a lower average personalization effect on retention, $d=0.30,(95 \% \mathrm{CI}$ : LL $=$ 0.18 to $\mathrm{UL}=0.41)$, than on transfer, $d=0.54,(95 \% \mathrm{CI}: \mathrm{LL}=0.25$ to $\mathrm{UL}=0.83)$.

As predicted by Hypotheses 2 and 3, the personalized text led to a longer restudy phase and higher self-reported motivation than the standard text. This pattern of results is compatible with the interpretation that the personalized text increased students' motivation to master the contents of the science text. Nevertheless, the data only partially supported the hypothesis that increased motivation would mediate increased transfer performance. The indirect path (indicating an increase in transfer performance from personalization through motivation) was only significant for the self-paced duration of restudying (Hypothesis 4) but not for self-reported motivation (Hypothesis 5). This result strengthens the interpretation that increased learning motivation enhances performance particularly when it affects task involvement. Increased task involvement might be reflected in changing learning strategies, increased effort and attention, or in the allocation of additional learning time, as in our study. This view might also explain some of the inconsistent findings of previous studies. Personalization might have affected task involvement without being reflected in verbal reports (e.g., Ginns and Fraser 2010; Mayer et al. 2004; Moreno and Mayer 2000), for example, when the change in task involvement is unrelated to the contents of the self-report items. Moreover, reported increased motivation does not necessarily indicate that task involvement was intensified, for example, when the learning situation limits the learner's self-regulation.

\section{Limitations and perspectives}

This study corroborated the view that motivational variables may mediate the effect of personalization on learning performance, but the role motivation plays in this context is worth further exploration. Previous attempts to assess motivation in personalization studies have been problematic, the methods of which varied substantially on the learning contexts including their motivationally relevant aspects. Although in the present study a reliable short scale was used, the range of motivational facets assessed was limited. This might have limited the probability of detecting further mediation effects. A more comprehensive approach to the role motivation plays in the effects of personalized learning materials would be instructive. This approach should also include the employment of more comprehensive measures of motivation so that more motivationally relevant aspects of the learning situation can be assessed.

Future research should also consider nonmotivational explanations of the personalization effect. A most promising candidate is the schema-based self-reference effect. Several studies have shown that information that was subjected to self- 
reference judgments is easier to recall than information that was processed without individual reference to the learner (e.g., Rogers et al. 1977; ;ymons and Johnson 19.97.). A prominent explanation is that self-referenced information activates knowledge about oneself (self-schemata). Self-schemata are frequently accessed and well-structured so that they are expected to support the organization and encoding of new information. Thus, self-referenced information can more easily be recalled. As increased accessibility might support the transfer of knowledge to new problems, the self reference effect is a potential alternative explanation of our results that deserves further investigation.

Furthermore, text comprehension competences need to be considered. Most studies on the personalization effect did not include measures of text comprehension competences although, in the long run, such competences might interact with selfschemata and meta-knowledge which, in turn, is related to motivation. Therefore, future research should also focus possible links between motivation, personalization effect, and comprehension competences.

In summary, motivational and memory-based explanations of the personalization effect present promising perspectives. Although explanations of the personalization effect remain to be explored, the present study demonstrated that a purely linguistic personalization of a science text is able to enhance learning performance in a classroom setting-mediated by increased task involvement.

\section{Footnotes}

1. 1.

We conducted the same analysis with prior knowledge as a covariate. Whereas the covariate was significant, $F(1,56)=12.55, p=0.001$, its interactions with the experimental factors were not. In this analysis, the personalization effect slightly increased, $F(1,56)=25.96, p<0.001, d=1.29$, (95 \% CI: $\mathrm{LL}=0.785$ to $\mathrm{UL}=1.795)$, compared to not controlling for prior knowledge $(\Delta d=0.174)$.

\section{Notes}

Stephan Dutke. Institute for Psychology in Education, University of Muenster, Fliednerstr. 21, 48149, Münster, Germany. Email: stephan.dutke@psy.unimuenster.de

Current themes of research:

Learning strategies. Effects of physical exercise on executive processing. Teaching psychology.

Most relevant publications in the field of Psychology of Education:

Leopold, C., Dörner, M., Leutner, D., \& S. Dutke (2015). Effects of strategy instructions on learning from text and pictures. Instructional Science, 43, 345-364. DOI

10.1007/s11251-014-9336-3 (https://doi.org/10.1007/s11251-014-9336-3). 
Barenberg, J., Berse, T., \& Dutke, S. (2015). Ergometer cycling enhances executive control in task switching. Journal of Cognitive Psychology, 27, 692-703.

doi: 10.1080/20445911.2015.1024256 (https://doi.org/10.1080

/20445911.2015.1024256)

Berse, T., Rolfes, K., Barenberg, J., Dutke, S., Kuhlenbäumer, G., Völker, K., Winter, B., Wittig, M., \& Knecht, S. (2015). Acute physical exercise improves shifting in adolescents at school: Evidence for a dopaminergic contribution. Frontiers in Behavioral Neuroscience, 9: 196. doi: 10.3389/fnbeh.2015.00196 (https://doi.org /10.3389/fnbeh.2015.00196)

Berse, T., Barenberg, J., Urban, V., \& Dutke, S. (2014). Agentic extraversion moderates the effect of physical exercise on executive shifting performance. Journal of Research in Personality, 52, 37-41.

Dutke, S., Jaitner, T., Berse, T., \& Barenberg, J. (2014). Acute physical exercise affected processing efficiency in an auditory attention task more than processing effectiveness. Journal of Sport and Exercise Psychology, 36, 69-79.

Dutke, S. \& Barenberg, J. (2015). Easy and informative: Using confidence-weighted true-false items for knowledge tests in psychology courses. Psychology Learning and Teaching. DOI: 10.1177/1475725715605627 (https://doi.org/10.1177

/1475725715605627)

Reddy, P., Dutke, S., Papageorgi, I., \& Bakker, H. (2014). Educating Europe. The Psychologist, 27, 928- 931.

Anna Christina Grefe. Institute for Psychology in Education, University of Muenster, Fliednerstr. 21, 48149, Münster, Germany

No previous publications

Claudia Leopold. Institute for Psychology in Education, University of Muenster, Fliednerstr. 21, 48149, Münster, Germany

Current themes of research:

Multimedia learning. Learning strategies.

Most relevant publications in the field of Psychology of Education:

Leopold, C. \& Mayer, R. E. (2015). An imagination effect in learning from scientific text. Journal of Educational Psychology, 107, 47-63.

Leopold, C., Dörner, M., Leutner, D., \& S. Dutke (2015). Effects of strategy instructions on learning from text and pictures. Instructional Science, 43, 345-364. DOI 10.1007/s11251-014-9336-3 (https://doi.org/10.1007/s11251-014-9336-3).

Leopold, C., Sumfleth, E. \& Leutner, D. (2013). Learning with summaries: Effects of representation mode and type of learning activity on comprehension and transfer. Learning and Instruction, 27, 40-49.

\section{Appendix}


Sample passage from the instructional text (translated from German):

\section{Standard text}

[...] The eye's adjustment to the distance of a focused object is called accommodation. Whereas in a camera, the distance between the lens and the film is adjusted, focusing in the human eye is affected by changing the concavity of the lens, that is, by changing its refraction power. This is the function of the ciliary muscle. [...]

\section{Personalized text}

[...] Your eye's adjustment to the distance of a focused object is called accommodation. Whereas in a camera, the distance between the lens and the film is adjusted, focusing in your eye is affected by changing the concavity of the lens, that is, by changing its refraction power. This is the function of your ciliary muscle. [...]

\section{References}

Anand, P., \& Ross, S. M. (1987). Using computer-assisted instruction to personalize math learning materials for elementary school children. Journal of Educational

Psychology, 79, 72-79.

CrossRef (https://doi.org/10.1037/0022-0663.79.1.72)

Google Scholar (http://scholar.google.com

/scholar_lookup?title=Using\%20computer-

assisted\%2oinstruction\%20to\%2opersonalize\%2omath\%2olearning\%2omaterials\%2 ofor\%2oelementary\%20school\%20children\&author=P.\%20Anand\&

author=SM.\%2oRoss\&journal=Journal\%20of\%2oEducational\%20Psychology\& volume $=79$ \&pages $=72-79$ \&publication $\_$year $=1987$ )

Baron, R. M., \& Kenny, D. A. (1986). The moderator-mediator variable distinction in social psychological research: conceptual, strategic, and statistical considerations.

Journal of Personality and Social Psychology, 51, 1173-1182.

CrossRef (https://doi.org/10.1037/oo22-3514.51.6.1173)

Google Scholar (http://scholar.google.com/scholar_lookup?title=The\%2omoderatormediator\%20variable\%2odistinction\%20in\%20social\%2opsychological\%2oresearch \%3A\%2Oconceptual\%2C\%20strategic\%2C\%20and\%2ostatistical\%2Oconsiderations\& author=RM.\%20Baron\&author=DA.\%20Kenny\&

journal=Journal\%20of\%2oPersonality\%20and\%20Social\%20Psychology\& volume $=51$ \&pages $=1173-1182 \&$ publication_year $=1986$ )

Bollen, K. A., \& Stine, R. (1990). Direct and indirect effects: classical and bootstrap estimates of variability. Sociological Methodology, 20, 115-140.

CrossRef (https://doi.org/10.2307/271084)

Google Scholar (http://scholar.google.com

/scholar_lookup?title=Direct\%20and\%2oindirect\%2oeffects \%3A\%20classical\%20and\%2obootstrap\%20estimates\%20of\%20variability\& author=KA.\%2oBollen\&author=R.\%20Stine\&journal=Sociological\%20Methodology\& volume $=20$ \&pages $=115-140$ \&publication_year $=1990$ )

Bretzing, B. H., \& Kulhavy, R. W. (1981). Note-taking and passage style. Journal of Educational Psychology, 73, 242-250. 
CrossRef (https://doi.org/10.1037/0022-0663.73.2.242)

Google Scholar (http://scholar.google.com/scholar_lookup?title=Note-

taking\%20and\%20passage\%20style\&author $=\mathrm{BH} . \% 20 B r e t z i n g \&$

author=RW.\%20Kulhavy\&journal=Journal\%20of\%20Educational\%20Psychology\&

volume $=73$ \&pages $=242-25$ o\&publication_year $=1981$ )

Brom, C., Bromová, E., Děchtěrenko, F., Buchtová, M., \& Pergel, M. (2014).

Personalized messages in a brewery educational simulation: is the personalization principle less robust than previously thought? Computers \& Education, 72, 339-366.

CrossRef (https://doi.org/10.1016/j.compedu.2013.11.013)

Google Scholar (http://scholar.google.com

/scholar_lookup?title=Personalized\%2omessages\%20in\%20a\%2obrewery\%2oeducati onal\%20simulation

\%3A\%20is\%20the\%2opersonalization\%2oprinciple\%2oless\%2orobust\%2othan\%2op reviously\%2othought\%3F\&author=C.\%20Brom\&author=E.\%20Bromov\%C3\%A1\& author=F.\%20D\%C4\%9Bcht\%C4\%9Brenko\&author=M.\%2oBuchtov\%C3\%A1\& author=M.\%20Pergel\&journal $=$ Computers $\% 20 \% 26 \% 20$ Education\&volume $=72 \&$ pages $=339-366 \&$ publication_year $=2014)$

Cordova, D. I., \& Lepper, M. R. (1996). Intrinsic motivation and the process of learning: beneficial effects of contextualization, personalization, and choice. Journal of Educational Psychology, 88, 715-730.

CrossRef (https://doi.org/10.1037/0022-0663.88.4.715)

Google Scholar (http://scholar.google.com

/scholar_lookup?title=Intrinsic\%2omotivation\%20and\%20the\%2oprocess\%20of\%20 learning\%3A\%2obeneficial\%20effects\%20of\%2ocontextualization \%2C\%2Opersonalization\%2C\%2Oand\%2Ochoice\&author=DI.\%20Cordova\& author=MR.\%20Lepper\&journal=Journal\%20of\%20Educational\%20Psychology\& volume $=88$ \&pages $=715-730 \&$ publication_year $=1996$ )

Davis-Dorsey, J., Ross, S. M., \& Morrison, G. R. (1991). The role of rewording and context personalization in the solving of mathematical word problems. Journal of Educational Psychology, 83, 61-68.

CrossRef (https://doi.org/10.1037/o022-0663.83.1.61)

Google Scholar (http://scholar.google.com

/scholar_lookup?title=The\%2orole\%20of\%2orewording\%20and\%20context\%2opers onalization\%20in\%2othe\%20solving\%20of\%2omathematical\%20word\%2oproblems \&author=J.\%20Davis-Dorsey\&author=SM.\%20Ross\&author=GR.\%20Morrison\& journal=Journal\%20of\%20Educational\%20Psychology\&volume=83\&pages $=61-68 \&$ publication_year=1991)

Dutke, S., Barenberg, J., \& Leopold, C. (2010). Learning from text: knowing the test format enhanced metacognitive monitoring. Metacognition and Learning, 5, 195-206. doi: 10.1007/s11409-010-9057-1 (https://doi.org/10.1007 /s11409-010-9057-1).

CrossRef (https://doi.org/10.1007/s11409-010-9057-1)

Google Scholar (http://scholar.google.com

/scholar_lookup?title=Learning\%2ofrom\%2otext

\%3A\%2oknowing\%20the\%2otest\%2oformat\%2oenhanced\%2ometacognitive\%2omo nitoring\&author $=\mathrm{S} . \% 20$ Dutke\&author $=$ J.\%20Barenberg\&author $=$ C.\%2OLeopold\& journal $=$ Metacognition $\% 20$ and $\% 20$ Learning\&volume $=5 \&$ pages $=195-206 \&$ publication_year $=2010 \& d o i=10.1007 \% 2 F s 11409-010-9057-1)$

Ginns, P., \& Fraser, J. (2010). Personalization enhances learning anatomy terms. Medical Teacher, 32, 776-778. doi: 10.3109/01421591003692714 (https://doi.org 
/10.3109/01421591003692714).

CrossRef (https://doi.org/10.3109/01421591003692714)

Google Scholar (http://scholar.google.com

/scholar_lookup?title=Personalization\%20enhances\%2olearning\%20anatomy\%2oter ms\&author=P.\%20Ginns\&author=J.\%2oFraser\&journal=Medical\%20Teacher\&

volume $=32$ \&pages $=776-778 \&$ publication $\_$year $=2010 \&$

doi $=10.3109 \% 2$ Fo1421591003692714)

Ginns, P., Martin, A. J., \& Marsh, H. W. (2013). Designing instructional text in a conversational style: a meta-analysis. Educational Psychology Review, 25, 445-472. CrossRef (https://doi.org/10.1007/s10648-013-9228-o)

Google Scholar (http://scholar.google.com

/scholar_lookup?title=Designing\%2oinstructional\%2otext\%20in\%20a\%20conversati onal\%20style\%3A\%20a\%2ometa-analysis\&author=P.\%20Ginns\&

author=AJ.\%20Martin\&author=HW.\%20Marsh\&

journal=Educational\%20Psychology\%20Review\&volume $=25 \&$ pages $=445-472 \&$

publication_year=2013)

Hayes, A. F. (2009). Beyond Baron and Kenny: statistical mediation analysis in the new millennium. Communication Monographs, 76, 408-420.

CrossRef (https://doi.org/10.1080/03637750903310360)

Google Scholar (http://scholar.google.com

/scholar_lookup?title=Beyond\%2oBaron\%2oand\%2oKenny

\%3A\%20statistical\%2omediation\%20analysis\%20in\%20the\%2onew\%2omillennium\& author=AF.\%20Hayes\&journal $=$ Communication\%20Monographs\&volume $=76 \&$

pages $=408-420$ \&publication $\_$year $=2009$ )

Herndon, J. N. (1987). Learner interests, achievement, and continuing motivation in instruction. Journal of Instructional Development, 10, 11-12.

CrossRef (https://doi.org/10.1007/BFo2905781)

Google Scholar (http://scholar.google.com

/scholar_lookup?title=Learner\%2ointerests\%2C\%20achievement

\%2C\%20and\%20continuing\%2omotivation\%20in\%2oinstruction\&

author $=\mathrm{JN} . \% 2 \mathrm{OHerndon} \&$

journal=Journal\%20of\%20Instructional\%20Development\&volume=10\&pages=11-12\& publication_year=1987)

Hidi, S. (1990). Interest and its contribution as a mental resource for learning. Review of Educational Research, 6o, 549-571.

CrossRef (https://doi.org/10.3102/00346543060004549)

Google Scholar (http://scholar.google.com

/scholar_lookup?title=Interest\%20and\%2oits\%20contribution\%20as\%20a\%2omenta 1\%20resource\%2ofor\%2olearning\&author=S.\%20Hidi\&

journal=Review\%20of\%2oEducational\%20Research\&volume=60\&pages $=549-571 \&$

publication_year=1990)

Hidi, S., \& Baird, W. (1988). Strategies for increasing text-based interest and students' recall of expository texts. Reading Research Quarterly, 23, 465-483.

CrossRef (https://doi.org/10.2307/747644)

Google Scholar (http://scholar.google.com

/scholar_lookup?title=Strategies\%2ofor\%2oincreasing\%2otext-

based\%2ointerest\%20and\%20students\%E2\%8o

\%99\%20recall\%20of\%20expository\%2otexts\&author=S.\%20Hidi\&

author=W.\%20Baird\&journal=Reading\%20Research\%20Quarterly\&volume=23\&

pages $=465-483 \&$ publication_year $=1988$ ) 
Kartal, G. (2010). Does language matter in multimedia learning? Personalization principle revisited. Journal of Educational Psychology, 102, 615-624.

doi: 10.1037/ao019345 (https://doi.org/10.1037/ao019345).

CrossRef (https://doi.org/10.1037/aoo19345)

Google Scholar (http://scholar.google.com

/scholar_lookup?title=Does\%2olanguage\%2omatter\%2oin\%2omultimedia\%2olearni ng\%3F\%20Personalization\%2oprinciple\%2orevisited\&author=G.\%2oKartal\& journal=Journal\%20of\%20Educational\%20Psychology\&volume $=102 \&$ pages $=615-624 \&$ publication_year $=2010 \&$ doi $=10.1037 \% 2 F a 0019345)$

Mayer, R. E. (2005). Principles of multimedia learning based on social cues: personalization, voice, and image principles. In R. E. Mayer (Ed.), The Cambridge handbook of multimedia learning (pp. 201-212). New York: Cambridge University Press.

CrossRef (https://doi.org/10.1017/CBO9780511816819.014)

Google Scholar (http://scholar.google.com

/scholar_lookup?title=Principles\%20of\%2omultimedia\%2olearning\%2obased\%20on \%20social\%2Ocues\%3A\%2opersonalization\%2C\%20voice \%2C\%20and\%2oimage\%2oprinciples\&author=RE.\%2oMayer\&pages=201-212\& publication_year=2005)

Mayer, R. E., Fennell, S., Farmer, L., \& Campbell, J. (2004). A personalization effect in multimedia learning: students learn better when words are in conversational style rather than formal style. Journal of Educational Psychology, 96, 389-395.

doi: 10.1037/0022-0663.96.2.389 (https://doi.org/10.1037/0022-0663.96.2.389). CrossRef (https://doi.org/10.1037/0022-0663.96.2.389)

Google Scholar (http://scholar.google.com

/scholar_lookup?title=A\%2opersonalization\%2oeffect\%2oin\%2omultimedia\%2olear ning

\%3A\%20students\%2olearn\%2obetter\%2Owhen\%20words\%20are\%20in\%2oconversa tional\%20style\%2orather\%2othan\%2oformal\%2ostyle\&author=RE.\%2oMayer\& author=S.\%20Fennell\&author=L.\%20Farmer\&author=J.\%20Campbell\& journal=Journal\%20of\%20Educational\%20Psychology\&volume=96\& pages $=389-395 \&$ publication_year $=2004 \& d o i=10.1037 \% 2$ Foo22-0663.96.2.389)

Moreno, R., \& Mayer, R. E. (2000). Engaging students in active learning: the case for personalized multimedia messages. Journal of Educational Psychology, 92, 724-733. doi: 10.1037//o022-0663.92.4.724 (https://doi.org/10.1037//0022-0663.92.4.724). CrossRef (https://doi.org/10.1037/0022-0663.92.4.724)

Google Scholar (http://scholar.google.com /scholar_lookup?title=Engaging\%2ostudents\%2oin\%2oactive\%2olearning \%3A\%20the\%20case\%2ofor\%2opersonalized\%2omultimedia\%2omessages\& author=R.\%20Moreno\&author=RE.\%20Mayer\& journal=Journal\%20of\%20Educational\%20Psychology\&volume=92\& pages $=724-733 \&$ publication $\_$year $=2000 \& d o i=10.1037 \% 2 F \% 2 F 0022-0663.92 .4 .724$ )

Moreno, R., \& Mayer, R. E. (2004). Personalized messages that promote science learning in virtual environments. Journal of Educational Psychology, 96, 165-173. doi: 10.1037/o022-0663.96.1.165 (https://doi.org/10.1037/0022-0663.96.1.165). CrossRef (https://doi.org/10.1037/0022-0663.96.1.165)

Google Scholar (http://scholar.google.com /scholar_lookup?title=Personalized\%2omessages\%2othat\%2opromote\%20science\%2 olearning\%20in\%20virtual\%20environments\&author=R.\%2oMoreno\& author=RE.\%20Mayer\&journal=Journal\%20of\%20Educational\%20Psychology\& 
volume $=96 \&$ pages $=165-173 \&$ publication_year $=2004 \&$

doi $=10.1037 \% 2$ Foo22-0663.96.1.165)

Moreno, R., Mayer, R. E., Spires, H. A., \& Lester, J. C. (2001). The case for social agency in computer-based teaching: do students learn more deeply when they interact with animated pedagogical agents? Cognition and Instruction, 19, 177-213.

CrossRef (https://doi.org/10.1207/S1532690XCI1902_02)

Google Scholar (http://scholar.google.com

/scholar_lookup?title=The\%20case\%2ofor\%20social\%20agency\%2oin\%20computerbased\%20teaching

\%3A\%20do\%20students\%2olearn\%2Omore\%20deeply\%20when\%20they\%2ointeract \%20with\%20animated\%2opedagogical\%20agents\%3F\&author=R.\%20Moreno\& author=RE.\%2OMayer\&author=HA.\%20Spires\&author=JC.\%2OLester\& journal=Cognition $\% 20$ and $\% 20$ Instruction\&volume $=19 \&$ pages $=177-213 \&$ publication_year=2001)

Preacher, K. J., \& Hayes, A. F. (2004). SPSS and SAS procedures for estimating indirect effects in simple mediation models. Behavior Research Methods, Instruments, \& Computers, 36, 717-731.

CrossRef (https://doi.org/10.3758/BFo3206553)

Google Scholar (http://scholar.google.com

/scholar_lookup?title=SPSS\%20and\%20SAS\%2oprocedures\%2ofor\%2oestimating\%2 oindirect\%2oeffects\%20in\%2osimple\%2omediation\%2omodels\& author=KJ.\%2OPreacher\&author=AF.\%20Hayes\& journal=Behavior\%2oResearch\%2oMethods\%2C\%2OInstruments\%2C\%20 $\% 26 \% 20$ Computers\&volume $=36 \&$ pages $=717-731 \&$ publication_year $=2004)$

Reeves, B., \& Nass, C. (1996). The media equation: how people treat computers, television, and new media like real people and places. New York: Cambridge University Press.

Google Scholar (http://scholar.google.com /scholar_lookup?title=The\%2omedia\%2oequation \%3A\%2ohow\%2opeople\%2otreat\%20computers\%2C\%20television \%2C\%20and\%2onew\%2omedia\%2olike\%2oreal\%2opeople\%20and\%2oplaces\& author=B.\%20Reeves\&author=C.\%20Nass\&publication_year=1996)

Renninger, K. A., Hidi, S., \& Krapp, A. (1992). The role of interest in learning and development. Hillsdale: Erlbaum.

Google Scholar (http://scholar.google.com /scholar_lookup?title=The\%2orole\%20of\%2ointerest\%2oin\%2olearning\%2oand\%20 development\&author=KA.\%20Renninger\&author=S.\%20Hidi\&author=A.\%20Krapp\& publication_year=1992)

Rogers, T. B., Kuiper, N. A., \& Kirker, W. S. (1977). Self-reference and the encoding of personal information. Journal of Personality and Social Psychology, 35, 677-688. doi: 10.1037/o022-3514.35.9.677 (https://doi.org/10.1037/0022-3514.35.9.677). CrossRef (https://doi.org/10.1037/o022-3514.35.9.677) Google Scholar (http://scholar.google.com/scholar_lookup?title=Selfreference\%20and\%2othe\%2oencoding\%20of\%2opersonal\%2oinformation\& author=TB.\%20Rogers\&author=NA.\%20Kuiper\&author=WS.\%20Kirker\& journal=Journal\%20of\%2oPersonality\%20and\%20Social\%20Psychology\& volume $=35 \&$ pages $=677-688 \&$ publication_year $=1977 \&$ doi $=10.1037 \% 2$ Foo22-3514.35.9.677)

Ross, S. M., \& Anand, P. (1987). A computer-based strategy for personalizing verbal 
problems in teaching mathematics. Educational Communication \& Technology Journal, 35, 151-162.

Google Scholar (http://scholar.google.com/scholar_lookup?title=A\%20computerbased\%20strategy\%2ofor\%2opersonalizing\%2overbal\%2oproblems\%2oin\%2oteachi ng\%20mathematics\&author=SM.\%20Ross\&author=P.\%20Anand\& journal=Educational\%20Communication\%20\%26\%20Technology\%20Journal\& volume $=35$ \&pages $=151-162 \&$ publication_year $=1987$ )

Ross, S. M., McCormick, D., \& Krisak, N. (1986). Adapting the thematic context of mathematical problems to student interests: individual versus group-based strategies. The Journal of Educational Research, 79, 245-252.

CrossRef (https://doi.org/10.1080/o0220671.1986.10885685)

Google Scholar (http://scholar.google.com

/scholar_lookup?title=Adapting\%20the\%2othematic\%20context\%20of\%2omathemat ical\%2oproblems\%2oto\%2ostudent\%2ointerests

\%3A\%2oindividual\%20versus\%2ogroup-based\%2ostrategies\&author=SM.\%20Ross\& author=D.\%20McCormick\&author=N.\%20Krisak\&

journal=The\%20Journal\%20of\%20Educational\%20Research\&volume=79\& pages $=245-252 \&$ publication_year $=1986$ )

Stiller, K. D., \& Jedlicka, R. (2010). A kind of expertise reversal effect: personalisation effect can depend on domain-specific prior knowledge. Australasian Journal of Educational Technology, 26, 133-149.

CrossRef (https://doi.org/10.14742/ajet.1107)

Google Scholar (http://scholar.google.com

/scholar_lookup?title=A\%2okind\%20of\%2oexpertise\%2oreversal\%2oeffect \%3A\%2opersonalisation\%2oeffect\%20can\%2odepend\%20on\%2odomainspecific\%2oprior\%2oknowledge\&author=KD.\%20Stiller\&author=R.\%2OJedlicka\& journal=Australasian\%20Journal\%20of\%2oEducational\%2oTechnology\& volume $=26$ \&pages $=133-149$ \&publication $\_$year $=2010$ )

Symons, C. S., \& Johnson, B. T. (1997). The self-reference effect in memory: a metaanalysis. Psychological Bulletin, 121, 371-394. doi: 10.1037/0033-2909.121.3.371 (https://doi.org/10.1037/0033-2909.121.3.371).

CrossRef (https://doi.org/10.1037/0033-2909.121.3.371)

Google Scholar (http://scholar.google.com/scholar_lookup?title=The\%20selfreference\%20effect\%20in\%2omemory\%3A\%20a\%2ometa-analysis\& author=CS.\%2OSymons\&author=BT.\%2OJohnson\& journal $=$ Psychological\%20Bulletin\&volume $=121 \&$ pages $=371-394 \&$ publication_year=1997\&doi=10.1037\%2Foo33-2909.121.3.371)

Wagner, L., Davis, S., \& Handelsman, M. M. (1998). In search of the abominable consent form: the impact of readability and personalization. Journal of Clinical Psychology, 54, 115-120.

CrossRef (https://doi.org/10.1002/(SICI)1097-4679(199801)54\%3A1<115

\%3A\%3AAID-JCLP13>3.0.CO\%3B2-N)

Google Scholar (http://scholar.google.com

/scholar_lookup?title=In\%20search\%20of\%20the\%20abominable\%20consent\%2ofor m\%3A\%20the\%2oimpact\%20of\%2oreadability\%2oand\%2opersonalization\& author $=$ L.\%20Wagner\&author $=$ S.\%20Davis\&author $=$ MM.\%2OHandelsman\& journal=Journal\%20of\%20Clinical\%20Psychology\&volume=54\&pages=115-120\& publication_year=1998) 


\section{Copyright information}

(C) Instituto Superior de Psicologia Aplicada, Lisboa, Portugal and Springer Science+Business Media Dordrecht 2015

\section{About this article}

Cite this article as:

Dutke, S., Grefe, A.C. \& Leopold, C. Eur J Psychol Educ (2016) 31: 499. https://doi.org/10.1007 /s10212-015-0281-6

- Received 22 September 2015

- Revised o7 December 2015

- Accepted 09 December 2015

- First Online 30 December 2015

- DOI https://doi.org/10.1007/s10212-015-0281-6

- Publisher Name Springer Netherlands

- Print ISSN 0256-2928

- Online ISSN 1878-5174

- About this journal

- $\underline{\text { Reprints and Permissions }}$

\section{Personalised recommendations}

1. Effects of task experience and layout on learning from text and pictures with or without unnecessary picture descriptions

Rop, Gertjan... van Gog, Tamara

Journal of Computer Assisted Learning (2018)

2. Kriteriengeleitetes Arbeiten - ein Aufgabenformat zur Förderung von selbstreguliertem Lernen im Mathematikunterricht

Nydegger, Annegret

Vielfältige Zugänge zum Mathematikunterricht (2019)

3. Measuring and investigating strategic knowledge about drawing to solve geometry modelling problems

Rellensmann, Johanna... Leopold, Claudia

$Z D M$ (2019)

Want recommendations via email? Sign up now Powered by: Recommended $\mathbf{R}$ 


\section{SPRINGER NATURE}

(C) 2019 Springer Nature Switzerland AG. Part of Springer Nature.

Not logged in University of Fribourg (1600004602) - BCU - Bibliothèque Cantonale et Universitaire (2000136229) - SWI Journal Cons (3000189246) - SWI Materials Consortium Konsortium der Schweizer (3000590661) Schweizer Nationallizenz (3003300383) - Konsortium der Schweizer Hochschulbibliotheken (3991445888) 134.21.138.93 